\title{
Research on Microstructure Evolution of Deposited Metal of Low Nickel High Nitrogen Austenitic Stainless Steel
}

\author{
Yiming Ma, ${ }^{1}$ Xiaochun Lv, ${ }^{1}$ Naiwen Fang $\left(\mathbb{D},{ }^{1}\right.$ Kai Xu, ${ }^{1}$ Xingxing Wang, ${ }^{2}$ Yicheng Yang, \\ Hongliang An, ${ }^{1}$ Yan Zhang, ${ }^{1}$ and Yinan $\mathrm{Xu}^{1}$ \\ ${ }^{1}$ Harbin Welding Institute Limited Company, 2077 Chuangxin Road Songbei District, Harbin, China \\ ${ }^{2}$ North China University of Water Resources and Electric Power, No. 36 Beihuan Road Jinshui District, Zhengzhou, China \\ Correspondence should be addressed to Naiwen Fang; naiwen20@163.com
}

Received 20 June 2021; Revised 9 October 2021; Accepted 25 October 2021; Published 16 November 2021

Academic Editor: kenji Kaneko

Copyright (C) 2021 Yiming Ma et al. This is an open access article distributed under the Creative Commons Attribution License, which permits unrestricted use, distribution, and reproduction in any medium, provided the original work is properly cited.

\begin{abstract}
In this paper, in situ observation of the cooling process of the deposited metal of low nickel high nitrogen austenitic stainless steel obtained by laser-arc hybrid surfacing welding with shielding gas containing only Ar and only $\mathrm{N}_{2}$, respectively, is carried out using the ultra-high-temperature confocal laser scanning microscope (CLSM). An in-depth analysis of the microstructural changes is conducted with SEM, EDS, and EBSD. The results showed that the surface substructure is refined during crystallization with shielding gas Ar. However, grains are seriously coarsened in the $\delta$ phase area. Widmanstatten $\gamma$ and intragranular $\gamma$ are formed as a result of $\delta \longrightarrow \gamma$ phase transition through the shear-diffusion mechanism. In the cooling process with shielding gas $\mathrm{N}_{2}$, the temperature range of each phase area narrowed obviously. Blocky $\gamma$ began to appear because of the $\delta \longrightarrow \gamma$ phase transition through the diffusion mechanism. Generally, Ar and $\mathrm{N}_{2}$ have a strong effect only on the very shallow range from the surface. The area with a larger local misorientation with shielding gas $\mathrm{Ar}$ is at lath $\gamma$ on the surface. With shielding gas $\mathrm{N}_{2}$, the large local misorientation area is the last contact position of $\gamma$ during the $\delta \longrightarrow \gamma$ phase transition on the surface and cross section.
\end{abstract}

\section{Introduction}

Cr-Ni stainless steel has been widely used in many critical fields in China because of its good plasticity, corrosion resistance, and weldability. However, due to the acute shortage of $\mathrm{Ni}$ resources, the development of resourcesaving stainless steel has become a need for China's sustainable economic growth. Low nickel high nitrogen austenitic stainless steel is an environmentally friendly and excellent performance material. Using austenite stabilizers such as $\mathrm{N}, \mathrm{Mn}$, and $\mathrm{Cu}, \mathrm{Ni}$ content is reduced from $8 \%$ to $3 \%$. However, it is easy to cause $\mathrm{N}$ to escape and produce pores during the welding. Therefore, its large-scale engineering application has been limited [1-4].

Domestic and foreign scholars have researched the weldability of low nickel high nitrogen austenitic stainless steel. Li [5] adopted double-shielded tungsten inert gas (TIG) welding. By using this method, the convection form of the molten pool is changed from outward convection to inward convection, which effectively transited the active element $\mathrm{O}$ to the molten pool and reduced the loss of N. Fang [6] used $\mathrm{Ar}+\mathrm{N}_{2}$ as shielding gas for welding and found that with the increase in $\mathrm{N}_{2}$ ratio, arc shrank, arc column width decreased, welding spattered, and arc stability became worse. Through the investigation of the influence of different welding methods on weld microstructure, it is found that $\gamma$ dendritic structure existed in weld microstructure of shielded metal arc welding (SMAW), reverted $\gamma$ appeared in the martensite in the fusion zone of gas tungsten arc welding (GTAW), and weld of electron beam welding (EBW) is made up of $\gamma$ matrix and discontinuous net-like $\delta$ [7]. In addition, when welding with higher heat input and faster cooling rate, primary $\delta$ in weld decreases and stress concentration is easily formed. The increase in dislocation density and Schmid factor of the weld resulted in higher tensile strength of the joint and lower yield strength [8].

The ultra-high-temperature confocal laser scanning microscope (CLSM) has been widely used to research phase 
transition, precipitation, and metallurgical process improvement for iron and steel materials [9, 10]. CLSM presents the microstructure and observes the in situ process through the selective evaporation of material surface heating (sublimation) or the difference of volume change and expansion between the old and new phases. Some achievements have been made in recent years to analyze the phase transition process of low nickel high nitrogen stainless steel using CLSM. Li [11] estimated that $\mathrm{N}_{2}$ pressure in the early stage of bubble burst is higher than $1.25 \times 10^{5} \sim 1.56 \times 10^{5} \mathrm{~Pa}$ based on the maximum diameter of $\mathrm{N}$ bubble and the surface tension of liquid phase by observing the floating, swimming, and bursting process of $\mathrm{N}$ bubble after the melting of high nitrogen steel. Tan [12] used $\mathrm{Cr}_{\mathrm{eq}} / \mathrm{Ni}_{\mathrm{eq}}$ value to predict the solidification mode of low nickel austenitic stainless steel, which is $\mathrm{L} \longrightarrow \mathrm{L}+\delta \longrightarrow \mathrm{L}+\delta+\gamma \longrightarrow \delta+\gamma$, and its reverse process is consistent with the observed melting process. Zhao [13] observed features of $\gamma \leftrightarrow \delta$ phase transition on the surface of stainless steel with different nitrogen contents and concluded that the migration of $\delta / \gamma$ interface is the main form in $\gamma \longrightarrow \delta$ phase transition. In $\delta \longrightarrow \gamma$ phase transition, $\gamma$ precipitated along the direction of $\delta / \delta$ grain boundaries with its longitudinal growth rate significantly faster than the transverse growth rate.

Although it is an economical and effective way to compensate for the loss of $\mathrm{N}$ by adding the appropriate amount of $\mathrm{N}_{2}$ to the shielding gas Ar [14], the effect of shielding gas on the microstructural change of weld has not been studied intensely and meticulously up to now. This paper uses CLSM and electron backscattered diffraction (EBSD) to analyze the microstructural changes of low nickel high nitrogen austenitic stainless steel weld using different shielding gases. It provides a more detailed comparison of the effects of different shielding gases on the weld microstructure in the welding process. It proposes a new idea for the optimization of the welding process and heat treatment process.

\section{Experiments}

The deposited metal samples are prepared by laser-metal active-gas (MAG) hybrid surfacing. The welding equipment included a KUKA robot, Fronius TPS4000 pulse welder, and an IPG YLS-6000 fiber laser. The laser front welding method is used. The laser power is $3.5 \mathrm{~kW}$, the distance between laser and arc is $6 \mathrm{~mm}$, and the defocusing amount is $+20 \mathrm{~mm}$. Parameters of MAG welding are shown in Table 1. The base material is $08 \mathrm{Cr} 19 \mathrm{MnNi} 3 \mathrm{Cu} 2$ low nickel high nitrogen austenitic stainless steel plate with $\delta=20 \mathrm{~mm}$, and the filling metal is ER307Si wire with $\varphi=1.2 \mathrm{~mm}$. See Table 2 for their chemical composition.

After surfacing four layers of 20 welds with laser filler wire, samples and discs of $\Phi 7 \times 3 \mathrm{~mm}$ are taken from the deposited metal in the position shown in Figure 1. They are ground and polished. Then, in situ high-temperature observation is carried out with the ultra-high-temperature confocal laser scanning microscope (Lasertec, vl2000dxsvf17sp) with shielding gases $\mathrm{Ar}$ and $\mathrm{N}_{2}$. The samples are recorded as $\mathrm{A}$ and $\mathrm{N}$, respectively. The process of the in situ observation at high temperature is shown in Figure 2. Surface and cross section $\delta$ content is measured with a ferrite testing machine (Feritscope, FMP30) at the end of the observation. The microstructural changes on the surface and section of the sample are analyzed by using optical microscope (OM, Olympus, GX51), scanning electron microscope (SEM, Zeiss, EVO 18), energy dispersive spectroscopy (EDS), and electron backscatter diffraction (EBSD).

\section{Results and Discussion}

3.1. High-Temperature In Situ Observation. Figure 3 depicts the changing trend of phase transition temperature under shielding gases of $\mathrm{Ar}$ and $\mathrm{N}_{2}$. Compared with sample $\mathrm{A}$, the temperature of liquid phase line and solid phase line of sample $\mathrm{N}$ decreased by $66.3^{\circ} \mathrm{C}$ and $62.1^{\circ} \mathrm{C}$, respectively, and the temperature range of $\mathrm{L} \longrightarrow \delta$ phase transition decreased from $13.5^{\circ} \mathrm{C}$ to $8.4^{\circ} \mathrm{C}$, and the temperature range of the $\delta$ phase region is reduced from $228.0^{\circ} \mathrm{C}$ to $12.3^{\circ} \mathrm{C}$. For $\delta \longrightarrow \gamma$ phase transition, the starting and ending temperature increased significantly, with the temperature range reducing from $474.5^{\circ} \mathrm{C}$ to $164.8^{\circ} \mathrm{C}$. Under the shielding gas of $\mathrm{N}_{2}$, the $\mathrm{L}+\delta$ phase area of the material moved down and slightly shrank, the $\delta$ and $\delta+\gamma$ phase areas are compressed, and $\gamma$ phase area enlarged significantly.

Both samples are $\mathrm{L}$ (liquid phase) at $1530^{\circ} \mathrm{C}$, and the crystallization process occurs in the next slow cooling stage $\left(1530^{\circ} \mathrm{C} \sim 1400^{\circ} \mathrm{C}\right)$. Whether crystallized under the protection of $\mathrm{Ar}$ or $\mathrm{N}_{2}$, only the $\mathrm{L} \longrightarrow \delta$ phase transition occurred and dendrites grew in the form of dendrite. At the end of crystallization, primary and tertiary dendrite arms are identified in Figure 4(a), while only tertiary dendrite arms are found in Figure 4(d). Compared with the tertiary dendrite arm spacing, the crystallization temperature of sample $\mathrm{A}$ is higher, and its crystallization temperature range is more extensive. The dendrite growth trend is less than sample N. The substructure coarsened when the sample crystallizes in $\mathrm{N}_{2}$. Grain boundary migration is observed immediately after crystallization, resulting in grain growth. At this time, there are no complete grains in the field of view of sample A, and the grain boundaries are flat (see Figure 4(b)), indicating abnormal grain growth in the $\delta$ phase. Specimen $\mathrm{N}$ has more grains, and multiple trigeminal boundaries are visible (see Figure 4(e)).

The $\mathrm{N}$ content on the surface of sample $\mathrm{N}$ is high according to the following text. The surface $\mathrm{N}$ combines with $\mathrm{Cr}$ to form $\mathrm{Cr}_{2} \mathrm{~N}$ [15]. The $\mathrm{Cr}_{2} \mathrm{~N}$ can play the role of grain refinement [16]. However, sample A did not contain $\mathrm{N}$ on the surface. It caused the grains to grow significantly. Therefore, although the dendritic arms coarsen during crystallization with shielding gas of $\mathrm{N}_{2}, \mathrm{~N}_{2}$ inhibited grain growth in the $\delta$ phase area plays an essential role in grain refinement.

In $\delta \longrightarrow \gamma$ phase transition process, grain boundaries are observed with no evident growth and $\delta+\gamma$ dual-phase microstructure is finally formed. $\delta$ content on the surface of sample $A$ is higher, while that on the surface of sample $\mathrm{N}$ is lower. When cooled in Ar, $\gamma$ nucleated in the grain boundary 
TABle 1: Parameters of MAG welding.

\begin{tabular}{lccccccc}
\hline Shielding gas & $\begin{array}{c}\text { Gas flow } \\
Q\left(\mathrm{~L} \cdot \mathrm{min}^{-1}\right)\end{array}$ & Current $I(\mathrm{~A})$ & Voltage $U(\mathrm{~V})$ & $\begin{array}{c}\text { Welding speed } v \\
\left(\mathrm{~mm} \cdot \mathrm{s}^{-1}\right)\end{array}$ & $\begin{array}{c}\text { Wire extension } \\
\text { length } l(\mathrm{~mm})\end{array}$ & $\begin{array}{c}\text { Welding torch } \\
\text { angle } a\left({ }^{\circ}\right)\end{array}$ & $\begin{array}{c}\text { Laser incidence } \\
\text { angle } \theta\left({ }^{\circ}\right)\end{array}$ \\
\hline $98 \% \mathrm{Ar}+2 \% \mathrm{~N}_{2}$ & 20 & 180 & 28 & 6.7 & 18 & 40 \\
\hline
\end{tabular}

TABLe 2: Chemical compositions of base metal and filler metal (wt.\%).

\begin{tabular}{lccccccccccccc}
\hline & $\mathrm{C}$ & $\mathrm{Si}$ & $\mathrm{Mn}$ & $\mathrm{P}$ & $\mathrm{S}$ & $\mathrm{Cr}$ & $\mathrm{Ni}$ & $\mathrm{Mo}$ & $\mathrm{Cu}$ & $\mathrm{N}$ & $\mathrm{V}$ & $\mathrm{Nb}$ & $\mathrm{Fe}$ \\
\hline 08Cr19MnNi3Cu2N & 0.071 & 0.40 & 6.60 & 0.040 & 0.001 & 18.20 & 2.90 & 0.11 & 1.80 & 0.245 & 0.125 & 0.01 & Bal. \\
ER307Si & 0.073 & 0.86 & 7.16 & 0.011 & 0.092 & 18.95 & 8.26 & 0.02 & 0.02 & 0.082 & - & 0.02 & Bal. \\
\hline
\end{tabular}

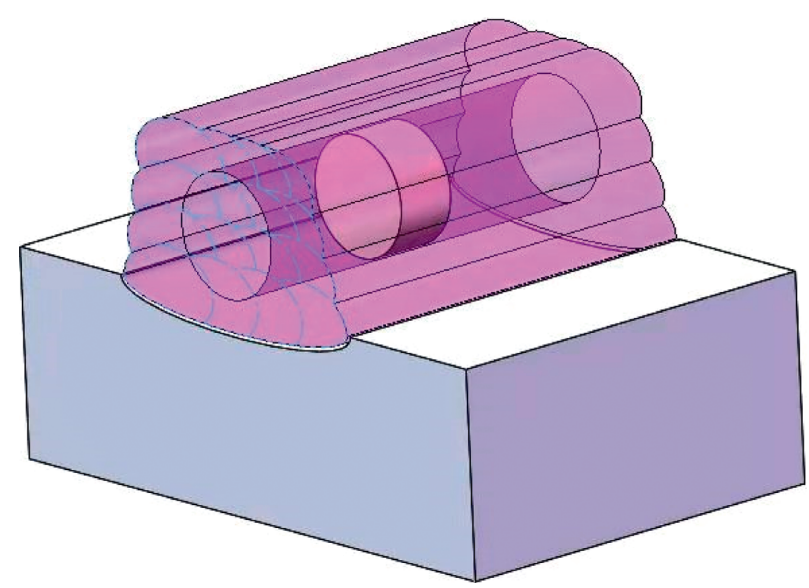

Figure 1: Sampling location.

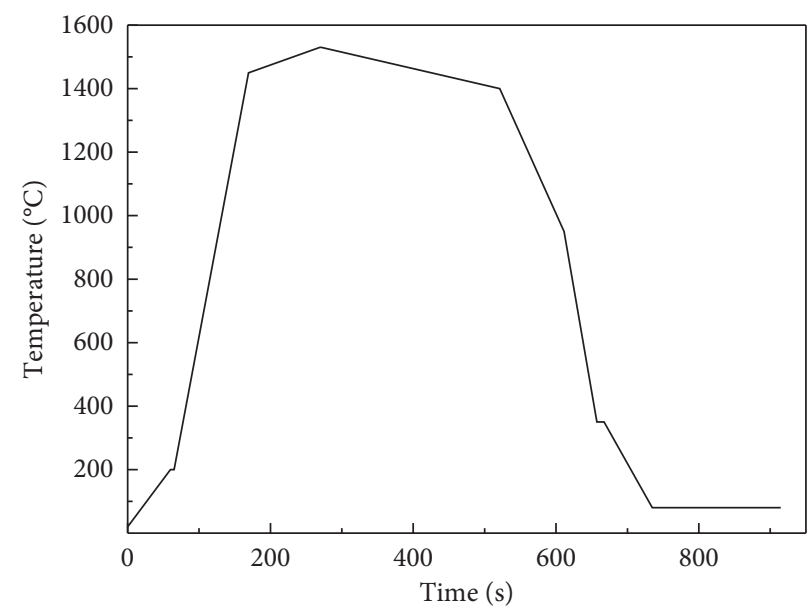

FIGURE 2: In situ observation test thermal process.

and formed acicular Widmanstatten $\gamma$. It also nucleated inside the grains and formed lath intragranular $\gamma$ [17]. The formation of $\gamma$ under these two conditions might cause surface relief. At the nucleation position, the adjacent Widmanstatten $\gamma$ is parallel, while nonadjacent ones crossover each other (see Figure $4(\mathrm{c})$ ). The reason is that there are only a few grain boundaries in sample A, and nuclei for $\gamma$ growth are not enough generated by the grain boundaries of the surface grains, resulting in intragranular nucleation. While cooled in $\mathrm{N}_{2}, \gamma$ nucleated between grain boundaries and dendrites and grew in blocky form. $\delta / \gamma$ phase boundary is curved and smooth, and the blocky $\gamma$ surface is flat and smooth, so finally, crystal-like morphology is formed (see Figure 4(f)). This is transformed from uneven lath or needles $\gamma$ into smooth equiaxed $\gamma$, and, internally smooth $\gamma$ illustrates that $\delta \longrightarrow \gamma$ phase transition changes 


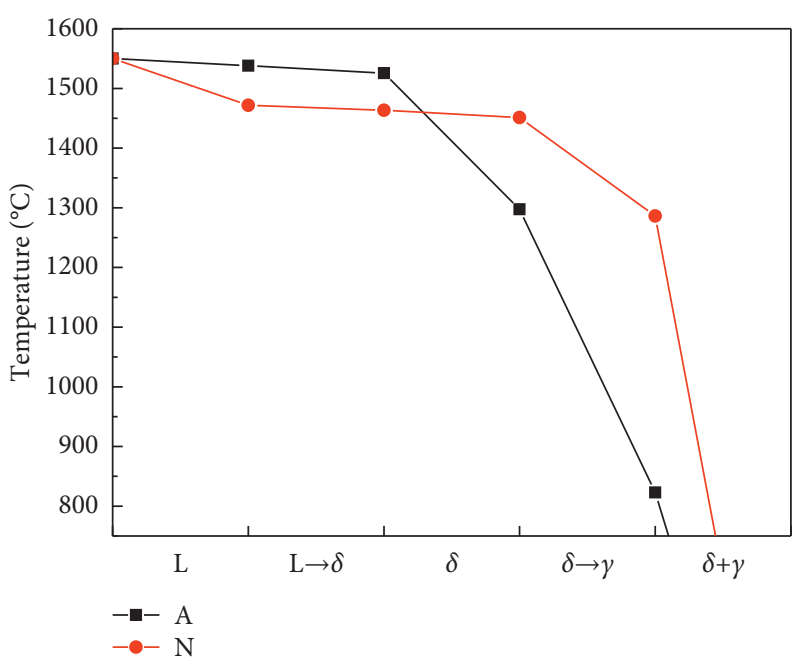

FIgURE 3: Phase transition temperature.

from partial shear form to complete diffusion form. The measurement showed that the average growth speed in the $\gamma$ length direction on the surface of sample A is $4.3 \mu \mathrm{m} / \mathrm{s}$ and that in the width direction is $2.2 \mu \mathrm{m} / \mathrm{s}$. The average growth rate of $\gamma$ on the surface of sample $\mathrm{N}$ is $0.3 \mu \mathrm{m} / \mathrm{s}$. It further proved that the shear mechanism involved in the surface phase transition under Ar and the diffusion mechanism involved under $\mathrm{N}_{2}$.

3.2. Surface Microstructure. There is a difference between the surface compositions of the two samples and the deposited metal (see Table 3). There occurred depletion of $\gamma$ stabilizers such as $\mathrm{N}$ and $\mathrm{Mn}$ on the surface of sample A, leading to the increase in $\delta$ stability and causing severe coarsening of grains at $\delta$ phase area temperature and the rise of $\delta$ content up to $23.66 \%$ at room temperature (see Figure 5). Significant Mn depletion and slight $\mathrm{Cr}$ enrichment occurred on the surface of the sample $\mathrm{N}$. The enrichment of $N$ made $\delta$ content at room temperature reduced to $1.38 \%$, lower than $4.31 \%$ of the deposited metal (see Figure 5). That is because, at high temperatures, the partial pressure of $\mathrm{N}_{2}$ under the shielding gas of Ar is zero, which made $\mathrm{N}$ atoms on the surface of the sample easy to combine into $\mathrm{N}$ molecules and then escaped. However, the high partial pressure under $\mathrm{N}_{2}$ made $\mathrm{N}$ atoms difficult to escape and caused the decomposition of $\mathrm{N}$ molecules in the shielding gas into $\mathrm{N}$ atoms and then dissolved into the sample's surface, thereby further reducing $\delta$ content [18].

There are few flat and straight grain boundaries on the surface of sample A, which indicates that the grains on the surface are very coarse (see Figure 6(a)). Acicular Widmannstatten $\gamma$ forms at the grain boundary. It can also nucleate in the crystal to form a lath intracrystal $\gamma$. It is consistent with the concave and convex surface morphology observed in situ. Compared with sample A, there are more grain boundaries on the surface of sample $\mathrm{N}$. The grain size significantly refines when intragranular $\gamma$ is in blocky form with smooth edges and shows significant growth (see Figure 6(d)).
The local misorientation of the two samples mainly distributes in $0^{\circ} \sim 2^{\circ}$. By comparing Figures 6(b) and 6(c) (or Figures 6(e) and 6(f)), it is found that the local misorientation of $\delta, \delta / \gamma$ phase boundary, and the large-angle grain boundary $\left(>10^{\circ}\right)$ is small. In sample A, the position with the larger local misorientation is lath-shaped and located in $\gamma$ and its surrounding $\delta$. The high-temperature in situ observation of sample $\mathrm{N}$ reveals that the blocky $\gamma$ became close to each other during the $\delta \longrightarrow \gamma$ phase transition. Finally a linear $\gamma$ is formed, in the area where the block $\gamma$ is about to contact during the $\delta \longrightarrow \gamma$ phase transition (see Figure 6(d)). The local orientation difference of sample $\mathrm{N}$ is almost less than $2^{\circ}$, which is far from the generally considered angle of the grain boundary $\left(>8^{\circ}\right.$ or $\left.10^{\circ}\right)$. Therefore, the linear area with a high level of local misorientation is not the grain boundary but the final formation $\gamma$ in the grain. The local misorientation can qualitatively reflect the dislocation density of the material. The local misorientation of sample A is generally higher than that of sample $\mathrm{N}$ (see Figures $6(\mathrm{~b})$ and $6(\mathrm{e})$ ), so there are more dislocations during the $\delta \longrightarrow \gamma$ phase transition under the shielding gas of Ar.

In addition, the large-angle grain boundary of sample A is located at the $\delta / \gamma$ phase boundary, while that of sample $\mathrm{N}$ is located between $\gamma$ (see Figures 6(c) and 6(f)). According to the in situ observation, the characteristics of the $\delta \longrightarrow \gamma$ phase transition on the surface of sample A are similar to dual-phase steel. Due to the escape of $\mathrm{N}$ from the surface, $\delta$ became difficult to desolvate and transformed into $\gamma \cdot \gamma+\delta$ lath with high dislocation density forms through a shear mechanism under a high degree of supercooling. By increasing the nitrogen on the surface of the sample $\mathrm{N}$, the $\delta \longrightarrow \gamma$ phase transition can form the block $\gamma$ with a lower dislocation density through the diffusion mechanism under a small degree of undercooling.

3.3. Cross Section Microstructure. The chemical composition of the cross section of the two samples shows little difference from that of the deposited metal (see Table 4). The cross 


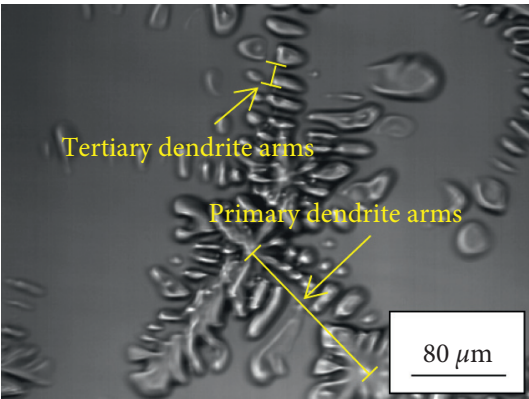

(a)

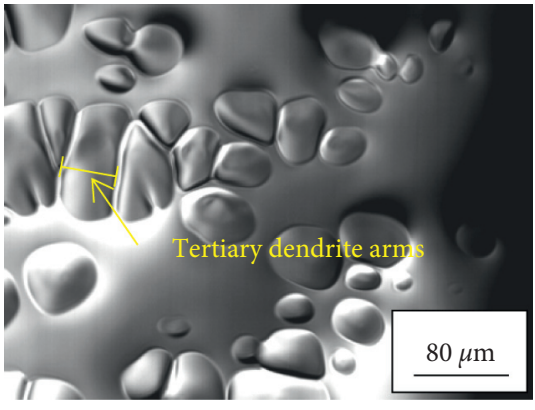

(d)

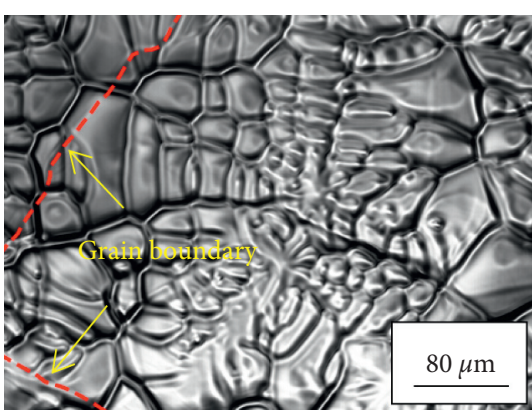

(b)

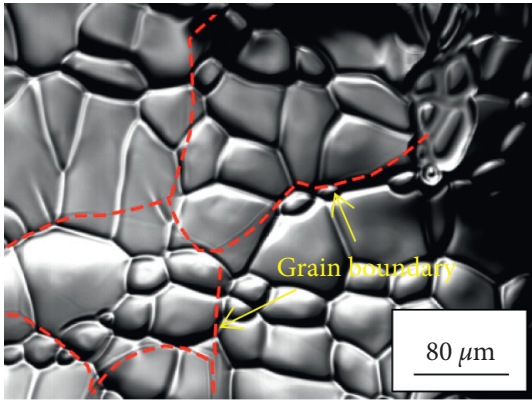

(e)

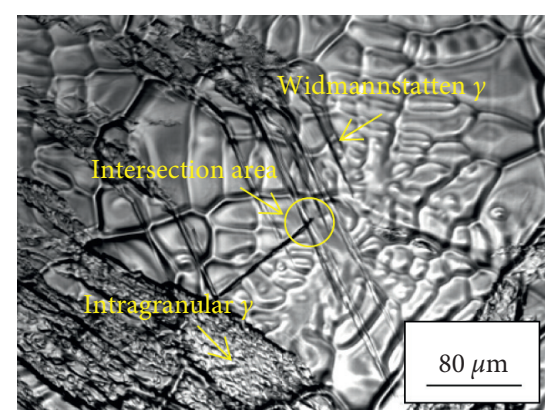

(c)

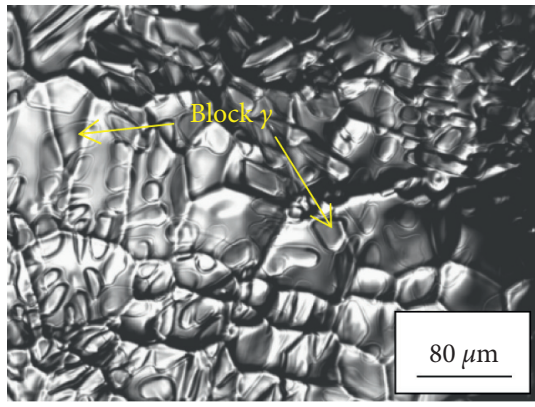

(f)

Figure 4: High-temperature microstructure: (a) sample A crystallized at 1528 ; (b) $\delta$ phase of sample A at $1310^{\circ} \mathrm{C}$; (c) sample A $962^{\circ} \mathrm{C} \delta \longrightarrow \gamma$ phase transition at $962^{\circ} \mathrm{C}$; (d) sample $\mathrm{N}$ crystallized at $1468^{\circ} \mathrm{C}$; (e) $\delta$ phase of sample $\mathrm{N}$ at $1454^{\circ} \mathrm{C}$; (f) sample $\mathrm{N}$ is in $\delta \longrightarrow \gamma$ phase transition at $1415^{\circ} \mathrm{C}$.

TABLE 3: Surface EDS analysis results (wt.\%).

\begin{tabular}{lccccccc}
\hline & $\mathrm{N}$ & $\mathrm{Si}$ & $\mathrm{Cr}$ & $\mathrm{Mn}$ & $\mathrm{Ni}$ & $\mathrm{Cu}$ & $\mathrm{Fe}$ \\
\hline Sample A & 0.00 & 0.14 & 20.44 & 4.30 & 2.28 & 1.30 & Bal. \\
Sample N & 0.21 & 0.25 & 21.85 & 1.28 & 2.50 & 0.88 & Bal. \\
Deposited metal & 0.13 & 0.30 & 19.78 & 6.92 & 2.80 & 1.74 & Bal. \\
\hline
\end{tabular}

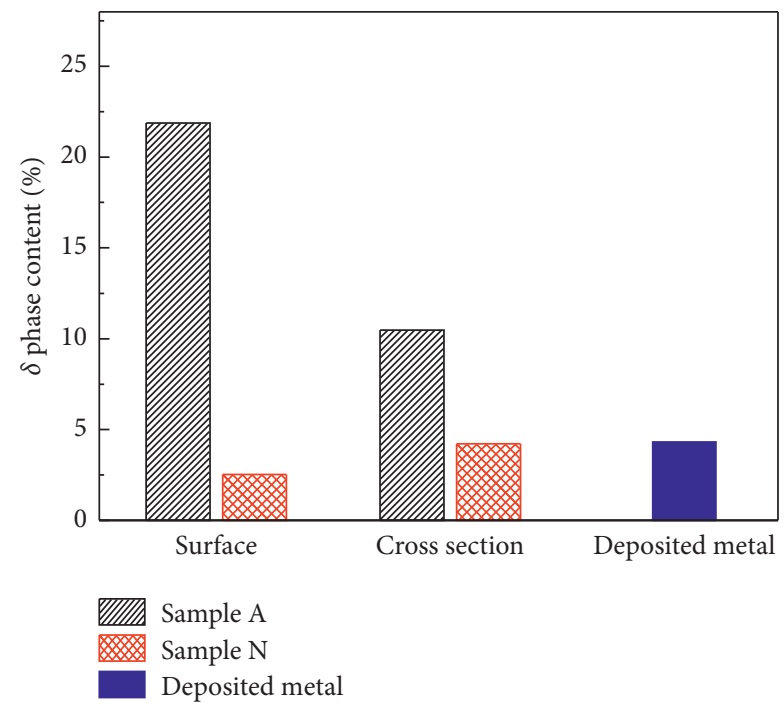

Figure 5: The $\delta$ content at room temperature.

sectional structure is $\gamma$ matrix $+\delta$ distributed between the dendrites. Compared with sample $\mathrm{N}$, the dendritic spacing of sample $\mathrm{A}$ is smaller and $\delta$ is coarser (see Figures 7(a) and 7(d)). It indicates that desolvation of internal $\mathrm{N}$ did not occur under the shielding gas of Ar, and a solid solution of internal sample $\mathrm{N}$ does not generate under $\mathrm{N}_{2}$. 


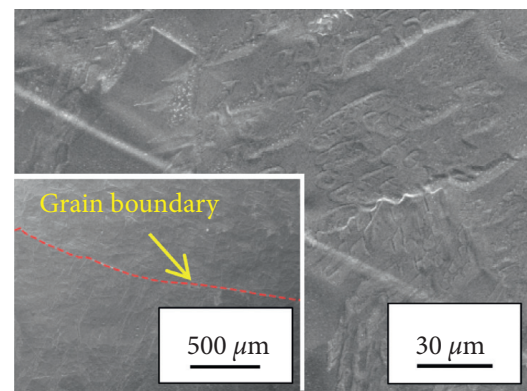

(a)

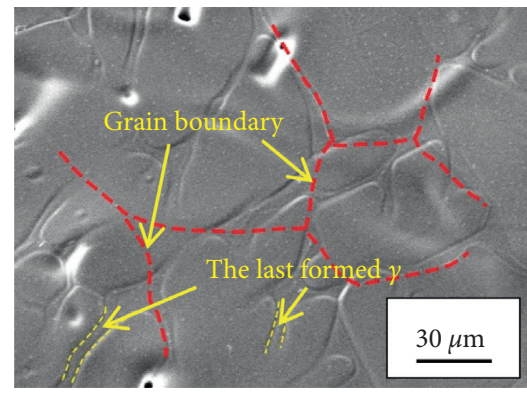

(d)

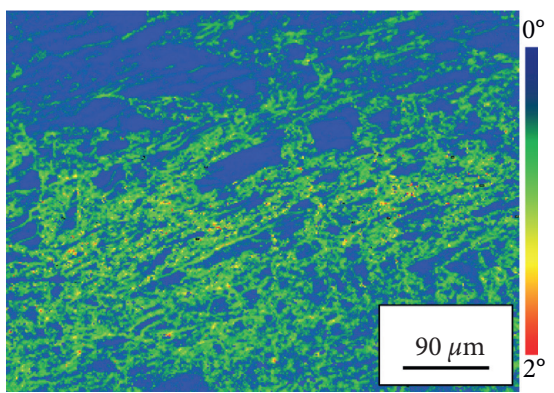

(b)

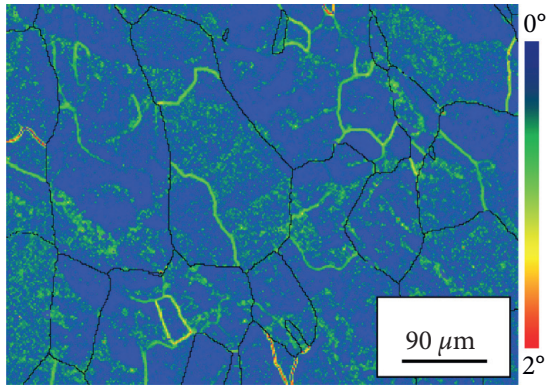

(e)

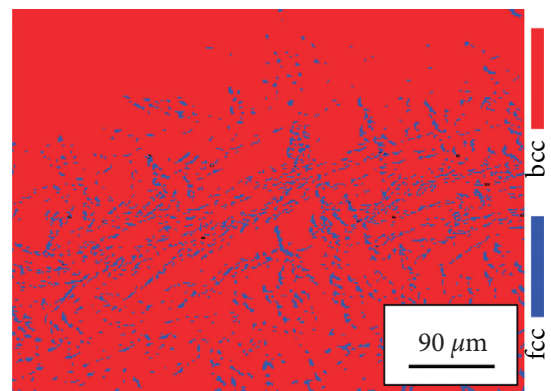

(c)

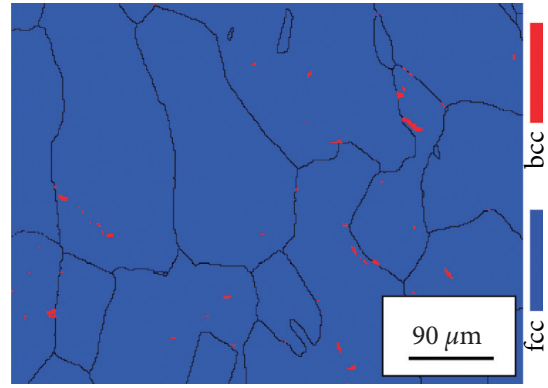

(f)

Figure 6: Surface structure and EBSD analysis results: (a) surface structure of sample A; (b) LocMis map of sample A; (c) phase map of sample A; (d) surface structure of sample N; (e) LocMis map of sample N; (f) phase map of sample N.

TABLE 4: Cross section EDS analysis results (wt.\%).

\begin{tabular}{lccccccc}
\hline & $\mathrm{N}$ & $\mathrm{Si}$ & $\mathrm{Cr}$ & $\mathrm{Mn}$ & $\mathrm{Ni}$ & $\mathrm{Cu}$ & $\mathrm{Fe}$ \\
\hline Sample A & 0.11 & 0.31 & 20.12 & 6.72 & 2.82 & 1.45 & Bal. \\
Sample N & 0.15 & 0.23 & 19.69 & 6.70 & 2.78 & 1.77 & Bal. \\
Deposited metal & 0.13 & 0.30 & 19.78 & 6.92 & 2.80 & 1.74 & Bal. \\
\hline
\end{tabular}

Compared with the surface, the $\delta$ content of the cross section of sample A is significantly reduced and that of sample $\mathrm{N}$ is increased to be equivalent to the deposited metal (see Figure 5). There is no significant difference between the near-surface area of the two samples and their internal structure (see Figures 7(a) and 7(d)). It shows that Ar and $\mathrm{N}_{2}$ only have a drastic effect on the very shallow range from the surface of the samples. Ar might change the internal $\delta \longrightarrow \gamma$ phase transition mechanism and increase the $\delta$ content, while $\mathrm{N}_{2}$ has little effect on the interior.

Similar to the $\delta \longrightarrow \gamma$ phase transition process on the surface, the local misorientation of the cross section of the two samples mainly distributes in $0^{\circ} \sim 2^{\circ}$. In the $\delta$ zone, local misorientation of $\delta / \gamma$ phase boundary and the large-angle grain boundary $\left(>10^{\circ}\right)$ is small. In the cross section of sample $\mathrm{A}$, the position with large local misorientation is located at the lath $\gamma+\delta$ and the curved line $\gamma$ (see Figure 7(b)). As for the cross section of the sample $\mathrm{N}$, it is only found at the curved line $\gamma$ (see Figure 7(e)). Comparing Figures 7(b) and $7(\mathrm{e})$, it is different from the surface phase transition process.
The level of local misorientation of sample A decreases, while the overall local misorientation of sample $\mathrm{N}$ remains unchanged. Therefore, the $\delta \longrightarrow \gamma$ phase transition inside the sample under the protection of Ar has a shear mechanism and the degree is lower than the surface, indicating that the phase transition mechanism is a shear-diffusion mixed form. In contrast, the $\delta \longrightarrow \gamma$ inside the sample phase transition is still a diffusion mechanism in $\mathrm{N}_{2}$.

Figures 7(c) and 7(f) show that the grains surrounded by the large-angle grain boundary of sample A are columnar and equiaxed, while sample $\mathrm{N}$ is nearly equiaxed. The microstructure of sample A is fine, but their size and shape are not uniform, forming a mixed grain structure. The plastic deformation of the mixed grain structure is very uneven and easy to produce stress and strain concentration. It will reduce the mechanical properties and process performance of the material $[19,20]$. Therefore, adding an appropriate amount of $\mathrm{N}_{2}$ to the welding shielding gas can compensate for the loss of $\mathrm{N}$ and help reduce the internal dislocation density and avoid the formation of a mixed crystal structure. 


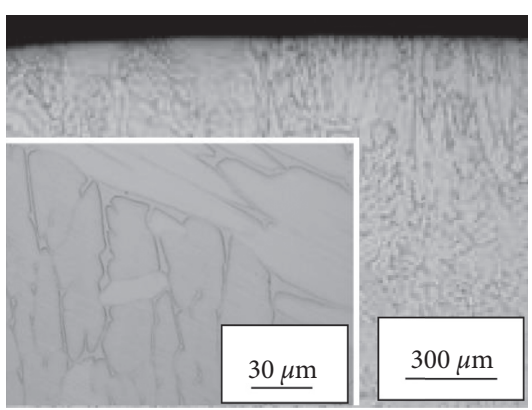

(a)

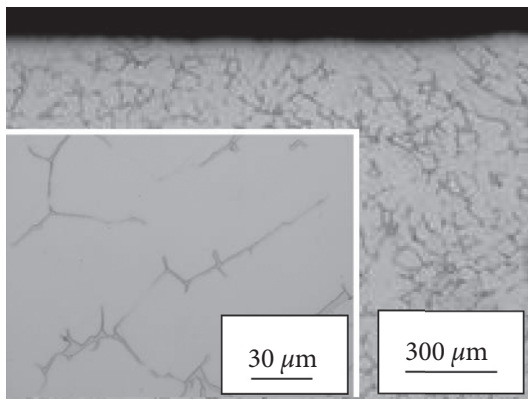

(d)

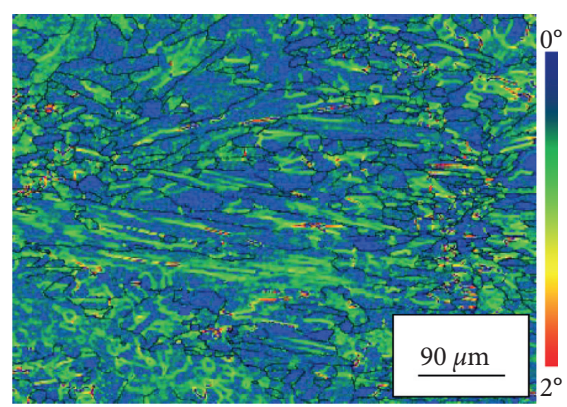

(b)

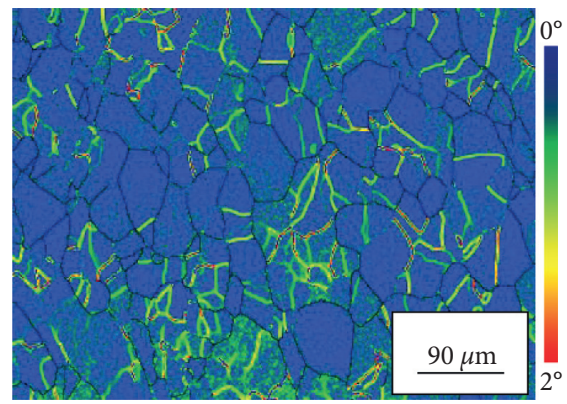

(e)

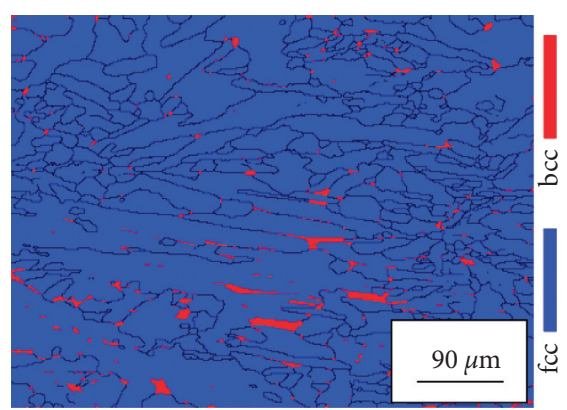

(c)

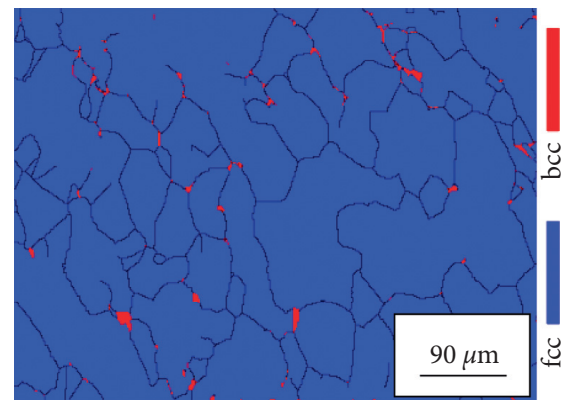

(f)

Figure 7: Cross section structure and EBSD analysis results: (a) cross section structure of sample A; (b) LocMis map of sample A; (c) phase map of sample A; (d) cross section structure of sample N; (e) LocMis map of sample N; (f) phase map of sample N.

\section{Conclusions}

(1) The surface substructure is refined during crystallization under the shielding gas of Ar. However, grains are seriously coarsened in the $\delta$ phase area. Widmanstatten $\gamma$ and intragranular $\gamma$ form during $\delta \longrightarrow \gamma$ phase transition. The temperature range of each phase area under shielding gas of $\mathrm{N}_{2}$ narrowed obviously, and blocky $\gamma$ appeared in the $\delta \longrightarrow \gamma$ phase transition.

(2) Under the shielding gas of Ar, $\mathrm{N}$ is exsolution and escaped, causing the sample to undergo a $\delta \longrightarrow \gamma$ phase transition of shear-diffusion mechanism. The phase transition temperature decreases, the transition speed increases, the residual $\delta$ content increases, and the dislocation density increases. However, Ar and $\mathrm{N}_{2}$ only affect a very shallow range from the surface, and the level of the shear mechanism inside the sample is significantly reduced.

(3) Regardless of what shielding gas Ar or $\mathrm{N}_{2}$ is used, the local misorientation between the surface and the cross section of the samples is relatively small at $\delta$, $\delta / \gamma$ phase boundary, and large-angle grain boundary $\left(>10^{\circ}\right)$. With $\mathrm{N}_{2}$ as the shielding gas, the area on the surface and on the cross section with a larger local misorientation is located where $\gamma$ finally contacts during the $\delta \longrightarrow \gamma$ phase transition. With Ar as the shielding gas, the area with the higher local misorientation level on the surface is located in lath $\gamma$ and on the cross section is located where $\gamma$ finally contacts and in lath $\gamma$.

\section{Data Availability}

The data included in this study are available from the corresponding author upon request.

\section{Conflicts of Interest}

The authors declare that there are no conflicts of interest regarding the publication of this paper.

\section{Acknowledgments}

This work was supported by Heilongjiang Provincial Fund for the National Project (GX18A001) and the Energy Equipment Advanced Welding Technology Innovation Team Fund supported by Heilongjiang Provincial Head Talent Plan (201910312).

\section{References}

[1] I. Woo and Y. Kikuchi, "Weldability of high nitrogen stainless steel," ISIJ International, vol. 42, no. No. 12, pp. 1334-1343, 2002.

[2] Y. Peng, L. Song, L. Zhao, C. Ma, H. Zhao, and Z. Tian, "Research status of weldability of advanced steel," Acta Metallurgica Sinica, vol. 56, no. 4, pp. 601-618, 2020.

[3] H. Vashishtha, R. V. Taiwade, S. Sharma, and A. P. Patil, "Effect of welding processes on microstructural and mechanical properties of dissimilar weldments between conventional austenitic and high nitrogen austenitic stainless steels," Journal of Manufacturing Processes, vol. 25, no. 1, pp. 49-59, 2017. 
[4] Y. Jiang, M. L. Cheng, H. H. Jiang et al., "Microstructure and properties of $08 \mathrm{Cr} 19 \mathrm{Mn} 6 \mathrm{Ni} 3 \mathrm{Cu} 2 \mathrm{~N}$ (QN1803) high strength nitrogen alloyed low nickel austenitic stainless steel," Acta Metallurgica Sinica, vol. 56, no. 4, pp. 642-652, 2020.

[5] D. J. Li, S. P. Lu, D. Z. Li, and Y. Li, "Investigation of the microstructure and impact properties of the high nitrogen stainless steel weld," Acta Metallurgica Sinica, vol. 49, no. 2, pp. 129-136, 2013.

[6] N. W. Fang, R. S. Huang, D. J. Yan, Y. Yang, Y. Ma, and B. Leng, "Effect of welding heatinput on microstructure and properties of MAG welded joint for low nickel high nitrogen austenitic stainless steel," Transactions of the China Welding Institute, vol. 43, no. 1, pp. 70-75+102, 2021.

[7] R. Mohammed, G. M. Reddy, and K. Srinivasa Rao, "Welding of nickel free high nitrogen stainless steel: microstructure and mechanical properties," Defence Technology, vol. 13, no. 2, pp. 59-71, 2017.

[8] J. Li, H. Li, Y. Liang, P. Liu, and L. Yang, "The microstructure and mechanical properties of multi-strand, composite welding-wire welded joints of high nitrogen austenitic stainless steel," Materials, vol. 12, no. 18, p. 2499, 2019.

[9] C. Wang, H. Wang, C. Zhang, J. K. Li, and S. L. Zhang, “A review on high temperature confocal scanning laser microscope applied in steel materials," Physics Examination and Testing, vol. 37, no. 6, pp. 15-26, 2019.

[10] G. J. Mao, R. Cao, X. L. Guo, Y. Jiang, and J. Chen, "In situ observation of kinetic processes of lath bainite nucleation and growth by laser scanning confocal microscope in reheated weld metals," Metallurgical and Materials Transactions A, vol. 48, no. 11, pp. 5783-5798, 2017.

[11] G. Q. Li, M. X. Guo, F. Zhang, C. Y. Zhu, B. Bart, and W. Patrick, "In-situ observation of nitrogen release and phase transformation of high nitrogen steels," Journal of Wuhan University of Science and Technology (Social Science Edition), vol. 31, no. 5, pp. 457-463, 2008.

[12] W. Tan, G. S. Ji, J. B. Zhang, J. G. Jia, and X. L. Nan, "In situ observation of $\gamma$-austenite to $\delta$-ferrite phase transformation in a nickel-saving austenitic stainless steel during heating," Transactions of Materials and Heat Treatment, vol. 32, no. 10, pp. 90-95, 2011.

[13] Y. Zhao, Y. H. Sun, X. B. Li, and F. Song, "In-situ observation of $\delta \leftrightarrow \gamma$ phase transitions in duplex stainless steel containing different nitrogen contents," ISIJ International, vol. 57, no. 9, pp. 1637-1644, 2017.

[14] Z. Brytan, J. Niagaj, and Ł. Reiman, "Corrosion studies using potentiodynamic and EIS electrochemical techniques of welded lean duplex stainless steel UNS S82441," Applied Surface Science, vol. 388, no. 6, pp. 160-168, 2016.

[15] H. Y. Wang, X. Y. Gao, J. C. Yang, Y. Jia, and J. Gong, "Firstprinciples study of $\mathrm{Cr}_{2} \mathrm{~N} / \gamma$-Fe interface in high nitrogen steel," Materials Transactions, vol. 56, no. 7, pp. 1047-1051, 2015.

[16] J. Y. Li, H. N. Liu, and W. P. Huang, "Effects of pre-precipitation of $\mathrm{Cr}_{2} \mathrm{~N}$ on microstructures and properties of high nitrogen stainless steel," Journal of Central South University, vol. 19, no. 5, pp. 1189-1195, 2012.

[17] A. Eghlimi, M. Shamanian, M. Eskandarian, A. Zabolian, and J. A. Szpunar, "Characterization of microstructure and texture across dissimilar super duplex/austenitic stainless steel weldment joint by austenitic filler metal," Materials Characterization, vol. 106, no. 8, pp. 208-217, 2015.

[18] Z. Q. Zhang, H. Y. Jin, L. Y. Xu, T. G. Zhang, and Y. T. Xu, "Research progress on microstructure and properties of welded joint of ferrite/austenite duplex stainless steel,"
Transactions of Materials and Heat Treatment, vol. 41, no. 5, pp. 13-27, 2020.

[19] X. H. Han, H. M. Zhang, Y. Q. Li, Y. Zhang, and Z. S. Cui, "Grain-level plasticity heterogeneities of the mixed-grain microstructure in 316LN stainless steel," Journal of Plasticity Engineering, vol. 26, no. 6, pp. 134-141, 2019.

[20] X. L. Liu, J. Ban, and Y. Lu, "Experimental study on elimination of mixed grain of $8 \mathrm{Cr} 4 \mathrm{Mo} 4 \mathrm{~V}$ steel," Hot Working Technology, vol. 47, no. 14, pp. 172-175, 2018. 